22. Ajmone-M. P., Garcia J.F., Lenstra J.A. On the Origin of Cattle: How Aurochs Became Cattle and Colonized the World // Evolutionary Anthropology. 2010. Vol. 19, № 4. P. 148-157.

23. Товкайло М.Т. Неоліт Степового Побужжя. К.: Шлях, 2005. 160 с.

24. Саблин М.В., Пантелеев А.В., Сыромятникова Е.В. Археозоологический анализ остеологического материала из неолитических свайных поселений Подвинья: хозяйство и экология // Труды Зоологического института РАН. 2011. Т. 315, № 2. С. 143-153.

25. Журавльов О.П., Котова Н.С. Тваринництво неолітичного населення України // Археологія. 1996. № 2. C. 13-17.

26. Давид А.И. Фауна млекопитающих мезолитических и неолитических поселений Республики Молдова // Vestigii arheologice din Moldova. Кишинев, 1997. С. 111-121.

27. Бибикова В.И. К изучению древнейших домашних лошадей Восточной Европы // Бюллетень
Московского общества испытателей природы. 1967. Т. 22, вып. 3. С. 106-118.

28. Бибикова В.И. К изучению древнейших домашних лошадей Восточной Европы // Бюллетень Московского общества испытателей природы. 1970. Т. 25, вып. 5. С. 118-126.

29. Кузьмина И.Е. Лошади Северной Евразии от плиоцена до современности // Труды Зоологического института РАН. 1997. Т. 273. 221 с.

30. Gaunitz C., Fages A., Hanghøj K., et al. Ancient genomes revisit the ancestry of domestic and Przewalski's horses // Science. 2018. DOI: 10.1126/science. aao3297.

31. Outram A.K., Stear N.A., Bendrey R., Olsen S., Kasparov A., Zaibert V., Thorpe N., Evershed R.P. Earliest horse harnessing and milking // Science. 2009. Vol. 323. P. 1332-1335.

Исследование было проведено при участии Зоологического института РАН (гос. тема № АAAAA17-117022810195-3).

\title{
ARCHEOLOGICAL ANALYSIS OF OSTEOLOGICAL MATERIAL OF RAKUSHECHNIY YAR SETTLEMENT WHILE STUDYING THE ECONOMY OF THE EARLY NEOLYTIC POPULATION
} (C) 2018

Sablin Mikhail Valerievich, candidate of biological sciences, senior researcher of Theriology Laboratory Zoological Institute of the Russian Academy of Sciences (Saint Petersburg, Russian Federation)

Abstract. The paper contains the study results of the settlement Rakushechny Yar fauna from the excavations of 2013-2017. It is a reference site for this region, because it has a unique stratigraphy. It was possible to determine 201 bones of mammals, birds and turtles at the early Neolithic layers of Rakushechny Yar. The fish remains at the settlement are numerous, but have not been investigated. The large ungulates were of the greatest importance here for the hunting. The largest number of the bones belongs to the red deer. Cutting the carcasses of this animal occurred at the settlement. It should be noted that the horse is represented by a wild form here. An important event was the appearance of domestic cows, sheep and pigs in this region. As a result of the analysis of the available osteological material we can confidently state that the process of domestication of these species passed long before the arrival of the settlers on the Don River. The Early Neolithic population in the Northern Black Sea Region, from our point of view, was heterogeneous in terms of material culture and, probably, the origins of the formation. It is possible that this is the reason for the difference in economic activity of people in that territory.

Keywords: archaeozoology; stratigraphy; osteological material; Holocene; Rostov Region; Rakushechny Yar; Don archaeological society; State Hermitage; Zoological Institute; early Neolithic; faunistic complex; hunting; domestication of ungulates; Northern Black Sea Coast.

УДК 902.903.023

Статья поступила в редакцию 05.06.2018

\section{КОМПЛЕКСНЫЕ ЭКСПЕРИМЕНТАЛЬНО-ТРАСОЛОГИЧЕСКИЕ И ЭТНОГРАФИЧЕСКИЕ ИССЛЕДОВАНИЯ КЕРАМИКИ: ТЕХНОЛОГИЯ ИЗГОТОВЛЕНИЯ И ОБЖИГ}

(C) 2018

Поплевко Галина Николаевна, кандидат исторических наук, старший научный сотрудник экспериментально-трасологической лаборатории Институт истории материальной культуры РАН (2. Санкт-Петербург, Российская Федераиия)

Аннотация. Комплексные экспериментально-трасологические и этнографические исследования керамики показаны на примере применения их к изучению технологических приемов изготовления древней керамики. В работе рассматривается использование разных методов исследования на примере материалов поселения Ракушечный Яр на Нижнем Дону и майкопской культуры на Северном Кавказе и данных этнографии. Экспериментальное моделирование плоскодонных сосудов эпохи неолита и круглодонных сосудов майкопской культуры приводится в качестве примера. Показано, что керамика в разные археологические эпохи изготавливалась с помощью нескольких приемов. Технику изготовления сосудов удалось смоделировать с помощью экспериментов. Исследование данных этнографии по технике изготовления круглодонных сосудов показывает, что методов моделирования разных сосудов намного больше. В работе представлены археологические, экспериментальные, трасологические и этнографические данные по изготовлению как плоскодонных, так и круглодонных сосудов с использованием техники выколотки. В последнее время с помощью этой техники была выполнена серия экспериментов по моделированию сосудов и последующего трасологического иссле- 
дования технологии изготовления их с помощью выколотки. Впервые автором показано использование сочетания разных приемов лепки при изготовлении неолитических сосудов. Приведены данные петрографии и экспериментов по обжигу сосудов.

Ключевые слова: археология; комплексное исследование керамики; этнографические исследования лепки керамики; трасологический анализ керамики; технологический анализ керамики; ручная лепка керамики; техника изготовления круглодонных сосудов; экспериментальное моделирование; петрографический анализ керамики.

Комплексные исследования керамики эпохи неолита на Нижнем Дону и эпохи ранней бронзы на Северном Кавказе целенаправленно проводятся автором при поддержке РФФИ с 2010 [1]. Результаты исследований опубликованы в серии статей автора, в них приведены аргументы по технологии изготовления керамики майкопской культуры, которую делали вручную, без использования гончарного круга, а с использованием разных подручных фрагментов и круглодонных мисок в качестве «поворотных устройств» без оси [2]. Первые данные таких исследований были опубликованы в работах автора еще в 2012-2013 гг. и вызвали критику и несогласие коллег и исследователей майкопской культуры, в частности С.Н. Кореневского. Однако многолетние исследования и комплексный подход к анализу археологических источников, предложенный автором, и многочисленные экспериментально-трасологические исследования и их публикация, с демонстрацией данных этнографии, убедили моих оппонентов в том, что технология изготовления майкопской керамики была связана с разными приемами ручной лепки или с сочетанием нескольких приемов в процессе изготовления сосуда. В ряде работ было показано использование разных технологических приемов и их сочетание при изготовлении сосудов на нескольких поселениях майкопской культуры [3-9]. Неоднократно автором приведены экспериментальные, трасологические и петрографические исследования керамики из неолитических слоев поселения Ракушечный Яр [6;10-20]. Вопреки мнению некоторых исследователей о только ручной ленточной лепке сосудов [21] и формовке лоскутным налепом [22-24], после длительных экспериментальных и трасологических исследований и сопоставлений образцов керамики, а также наблюдений по изготовлению керамики в современной этнографии считаю возможным еще раз констатировать, что изготовление неолитической керамики на многослойном поселении Ракушечный Яр на Нижнем Дону проводилось несколькими приемами: ручной лепкой лентами; лепкой на форме-основе и сочетанием ленточной лепки с последующей выколоткой стенок сосудов, для придания более плотной структуры и последующему заглаживанию поверхности сосудов отмученной однородной глиной другого состава. В настоящей работе более подробно будут показаны все приемы, которые были использованы при изготовлении неолитической керамики поселения Ракушечный Яр.

В Комплексной экспериментально-трасологической экспедиции ИИМК РАН в 2010-2016 гг. были экспериментально смоделированы не только разные способы лепки, но и условия обжига древней керамики, с целью выяснения возможности получения высокотемпературного обжига при проведении его в яме.

Формовка керамики была смоделирована разными приемами лепки: ленточным способом, выбива- нием, техникой выколотки с помощью деревянной лопаточки снаружи сосуда и каменной наковаленки изнутри, техникой проковки стенок сосудов - использование каменного песта снаружи и каменной наковаленки изнутри. Были проведены эксперименты по сочетанию приемов лепки при формовке сосуда.

Комплексные экспериментально-трасологические исследования показали, что при изготовлении древней керамики часто был использован не один прием, а сочетание двух разных приемов лепки в процессе формовки керамики. Так, при трасологическом исследовании керамики из нижних слоев поселения Ракушечный Яр было отмечено, что стенки керамики очень плотные без пор и пустот, не содержат видимой примеси. Плотность и однородность керамической массы отличается от керамики изготовленной только ручной лепкой. Эти наблюдения приводят к мысли, что при изготовлении керамики на поселении был использован не один прием, а несколько. Признаки этих приемов фиксируются на фрагментах керамики:

1) ручная лепка из лент или уплощенных в ленту жгутов в процессе лепки и последующее выравнивание стенок лопаточками или зубчатым штампом;

2) ручная лепка из лент или уплощенных жгутов на твердой форме-основе и выравнивание внешней поверхности лопаточками и внутренней руками;

3) ручная лепка из лент или уплощенных жгутов и последующая выколотка деревянной лопаточкой внешней поверхности сосуда на руке или с использованием каменной наковаленки внутри сосуда.

1. При экспериментальном моделировании из разных глин при ручной лепке лентами без использования основы формируется недостаточно ровная и гладкая внешняя и внутренняя поверхности. Помимо этого в разрезе стенки при исследовании под микроскопом мы можем отметить наличие микропор, вследствие недостаточной плотности при ручной лепке. Также следует отметить, что стыки лент в таком случае видны визуально, а под микроскопом они выглядят в виде протяженных микропор или микротрещин. Вероятно, именно с ручной лепкой связана и обработка внутренней поверхности зубчатым штампом (рис. 1: I-II; рис. 2: I-II). Такой прием оставляет грубые расчесы на внутренней поверхности и связан он с выравниванием всей поверхности сосуда, изготовленной лентами или уплощенными в ленту в процессе лепки жгутами или их лоскутами. Под лоскутным налепом в данном случае понимается использование в процессе лепки кусков лент или жгутов (лоскутов). В тех случаях, когда для выравнивания внутренних стенок используются деревянные или костяные лопаточки без зубчиков, поверхность остается гладкой, но стыки лент и поры видны под микроскопом. Для того, чтобы убрать неровности от стыков лент или их лоскутов, и понадобилось использовать зубчатый штамп или лопаточки для обработки с 
Поплевко Г.Н.

внутренней поверхности. Иногда разглаживание поверхности проводилось руками с одной или обеих сторон (рис. 3: 1, 5, 8). Возможно, в процессе выравнивания внутренней поверхности использовали и подлеп из аморфного куска глиняного теста, которое размазывали по поверхности с целью ее выравнивания. В нижних слоях эпохи неолита поселения Ракушечный Яр такой прием разглаживания внутренней поверхности сосудов зубчатым штампом встре- чается чаще, чем в более позднее время. Почти все венчики нижних 23-20 слоев имеют плоский срез и П-образный профиль, иногда пришлифованную поверхность (рис. 3: 1-4, 6, 8). Орнамент на керамику наносился по влажной или слабо подсушенной поверхности (рис. 3: 7), редко встречается прочерченный орнамент по хорошо подсушенной поверхности. Все донца плоские, изготовлены всеми предложенными приемами (рис. 4).

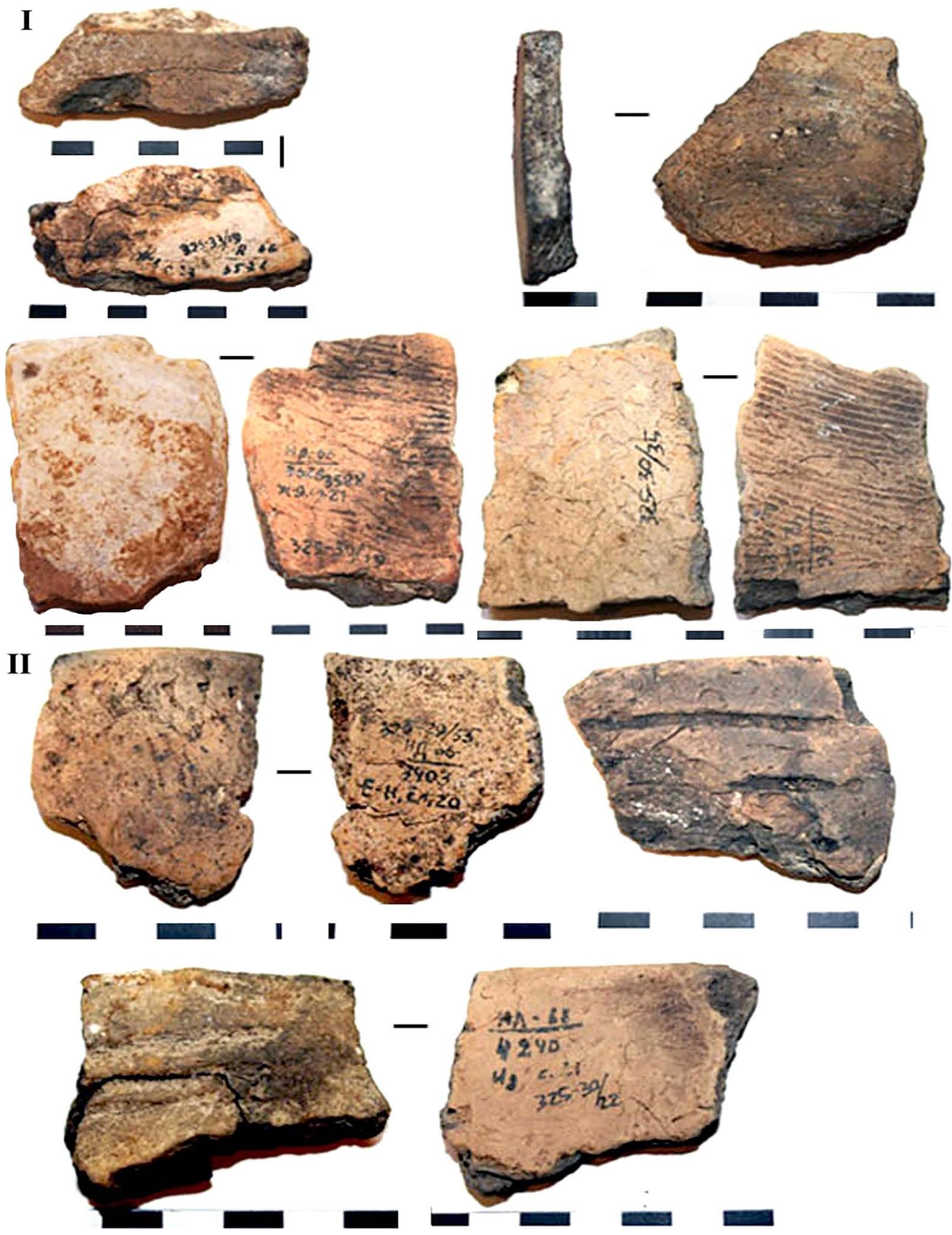

Рисунок 1 - Поселение Ракушечный Яр. Ручная ленточная лепка керамики.

I- керамика 23-21 слоев с расчесами зубчатым штампом на внутренней поверхности; II- венчики сосудов с орнаментом и заглаженной руками внутренней поверхностью 

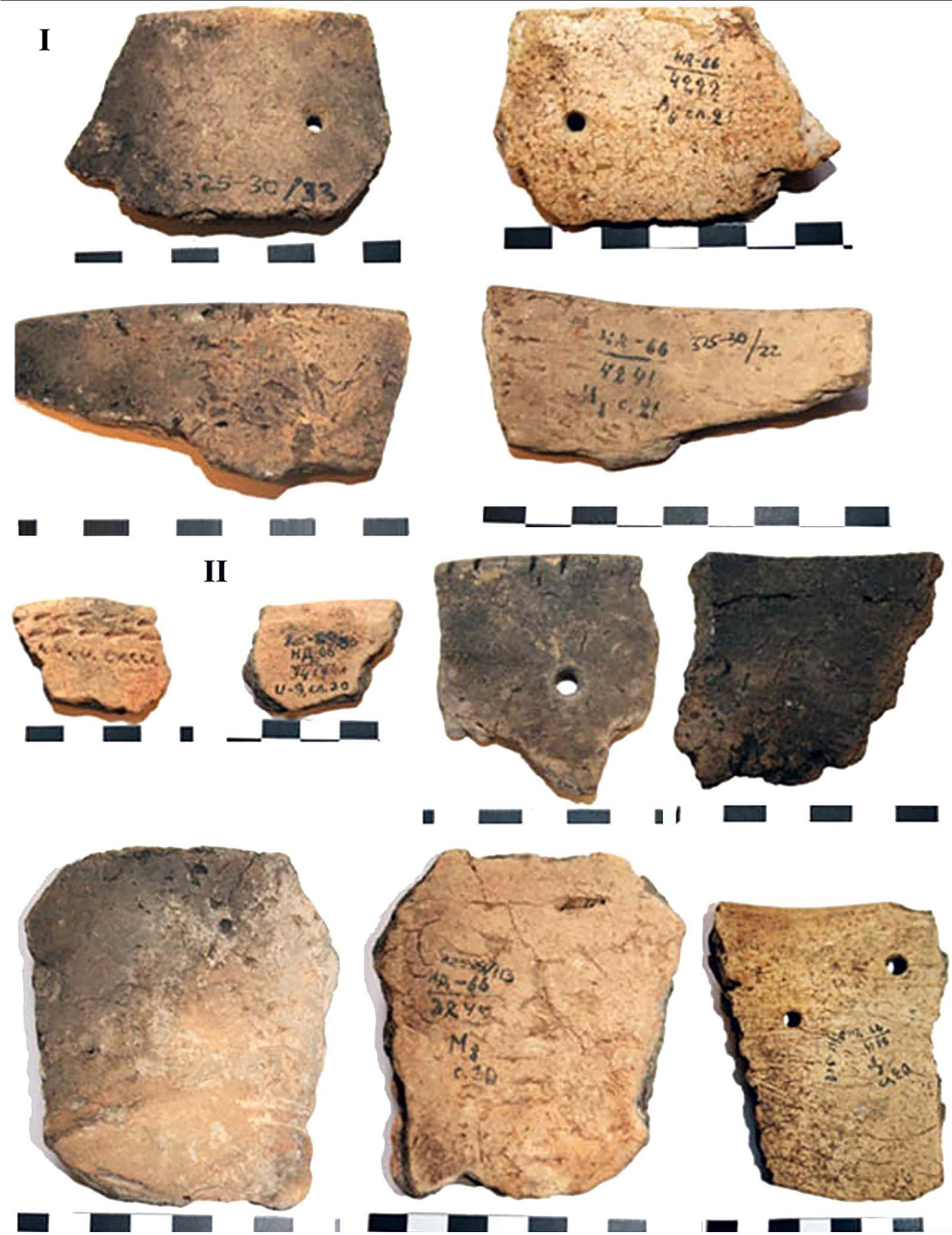

Рисунок 2 - Поселение Ракушечный Яр. Ручная ленточная лепка керамики.

I- венчики сосудов 21 слоя с отверстием и насечками по краю среза. Внутреняя поверхность заглажена; II- керамика 20 слоя с орнаментом, просверленными отверстиями и заглаженной руками внутренней поверхностью

2. Ручная лепка сосудов с использованием твердой формы-основы была использована при лепке и определяется по тонким плотным стенкам сосудов без пор и пустот, а также с плохо «читаемыми» стыками лент на фрагментах сосудов. Этот прием мог быть основным для изготовления сосудов, однако многократное моделирование показало, что при использовании илистой или гидрослюдистой глины из береговых отложений на поселении после обжига у нас получается более «легкий» черепок, чем археологический. Повторный анализ коллекции показывает, что более тонкие фрагменты керамики и фрагменты с тонким дном были изготовлены с использование именно этого приема лепки. Более плотные и толстые фрагменты были изготовлены по-другому. 




2


3

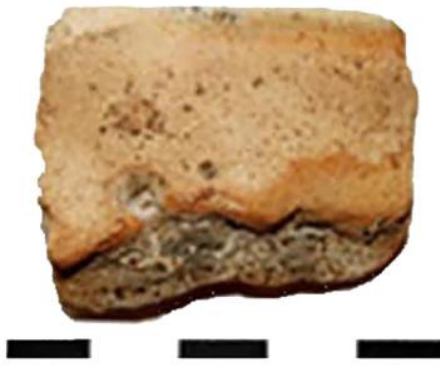

4
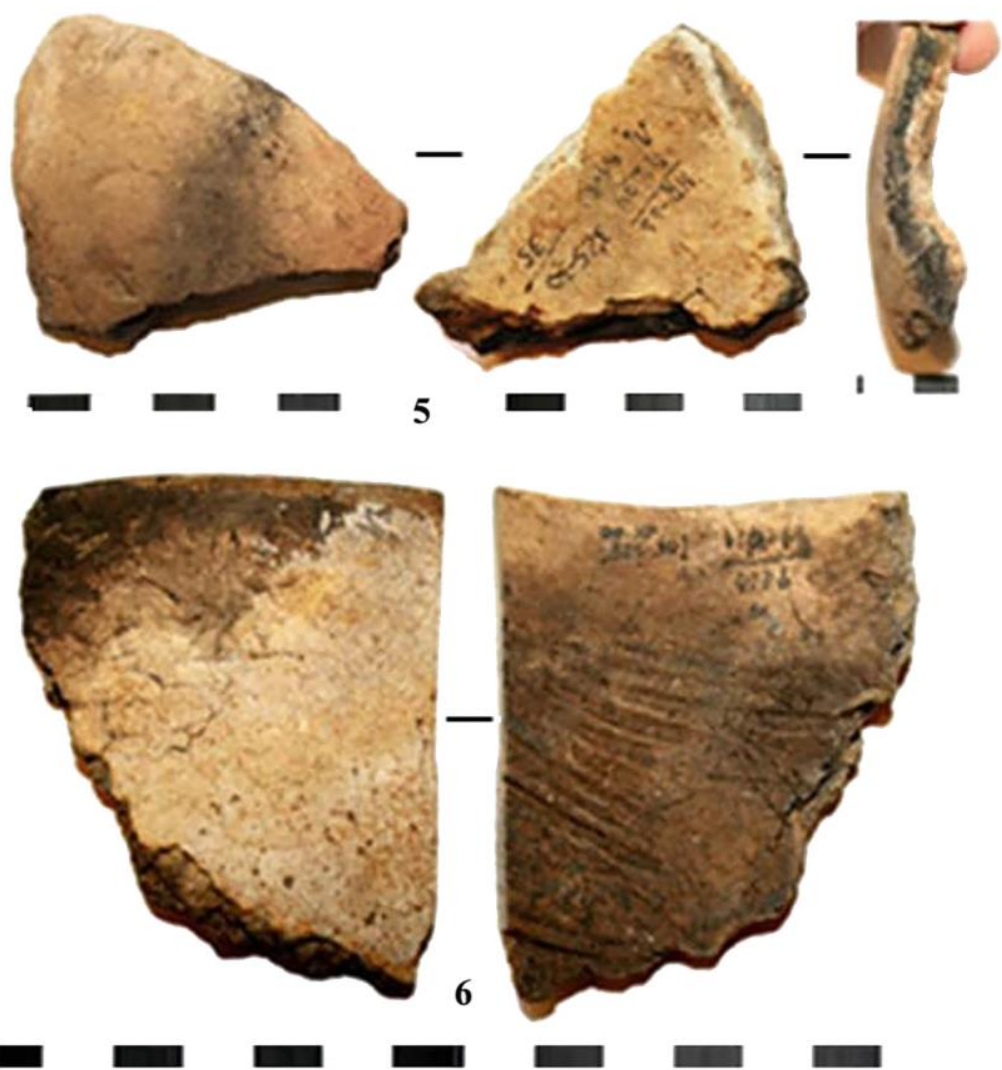

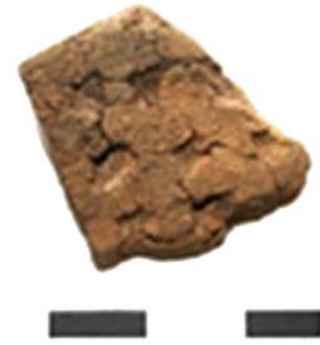

7

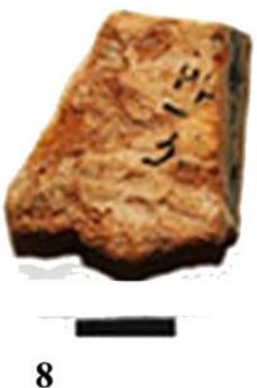

8

Рисунок 3 - Поселение Ракушечный Яр. Венчики сосудов 23-20 слоев.

Все венчики - 1-4, 6, 8 имеют прямой плоскосрезанный П-образный верх, иногда с пришлифовкой; 5- фрагмент с заглаженной руками внутренней поверхностью; 7- орнамент нанесен

на подсушенную поверхность, имеет четкую границу отпечатка орнаментира и микротрещины вокруг

3. Изготовление плотных, «тяжелых», однородных, камнеподобных, без пор и пустот в изломе стенок сосудов прослеживается на многих фрагментах из нижних слоев поселения Ракушечный Яр. Такую керамику надо соотносить с изготовлением двумя приемами лепки: $\mathbf{1 a}-$ ручная лепка лентами или жгутами, кольцевым или полукольцевым налепом, возможно и лоскутным налепом кусками лент или жгутов; $2 \boldsymbol{\sigma}$ - последующая выколотка стенок готово- го сосуда деревянной лопаточкой снаружи на руке или на каменной наковаленке внутри сосуда. Экспериментальные образцы показывают, что в таком случае мы получаем плотную структуру теста, практически не «читаются» участки стыка лент, нет пор, пустот. Фрагмент сосуда в изломе плотный, однородный, «тяжелый» после обжига, он практически идентичный археологическим образцам. Ранее автором в докладе «К проблеме комплексного исследо- 
Поплевко Г.Н.

Комплексные экспериментально-трасологические...

07.00.00 - исторические науки и археология

вания и реконструкции древней керамики» [25] было показано, что при лепке сосудов поселения Ракушечный Яр использовали эти приемы формовки сосудов. Основная часть сосудов была изготовлена именно таким способом. Замеры толщины стенок показывают, что жители поселения хорошо владели этими приемами, доводя до «стандарта» толщину стенок сосудов.


Рисунок 4 - Поселение Ракушечный Яр. Плоские донца сосудов 20 слоя.

1 - вид сбоку и вид в плане на разломанную часть донца. Ручная лепка, тесто рыхлое, расслаивается;

2- плоское донце, выполненное сочетанием ручной лепки и последующей выколотки деревянной колотушкой;

3- плоское донце, выполненное на форме-основе; 4- ручная лепка донца с отчетливым отпечатком

отслоившейся ленты: $a$ - вид с внутренней стороны в плане; б- вид на донце с внешней стороны в плане;

5 - ручная лепка и последующее разглаживание внутренней поверхности зубчатым штампом: $a$ - вид с внутренней стороны в плане; 6 - вид на донце с сбоку 
Этнографические наблюдения подтверждают, что такая практика сочетания приемов ручной лепки и последующей выколотки деревянной лопаточкой на каменной наковаленке или на подставленном изнутри более мелком сосуде, существует у современных народов, продолжающих традицию ручного изготовления керамики. Эти этнографические данные помогли провести серию экспериментов по использованию сочетания разных приемов при изготовлении сосуда.

Петрографические и другие естественнонаучные исследования показывают, что для формовки керамики эпохи неолита часто использовали большое количество отощителя или глины с естественными включениями и большой концентрацией алевролита или кварца. Часто в качестве примесей использовали измельченную ракушку, шамот или органику. Для лепки в нижних слоях поселения Ракушечный Яр были использованы глины (тощие), алевритовые, гидрослюдистого состава, обогащенные карбонатом. Для более позднего времени на поселениях эпохи бронзы были использованы более разнообразные составы глин при изготовлении керамики.

В Комплексной экспериментально-трасологической экспедиции ИИМК РАН также были проведены серии экспериментов, направленные на проверку гипотезы об использовании сочетания двух видов глин при приготовлении формовочной массы. К примеру, смешение тощих и жирных глин для снижения процесса усадки сосудов при их обжиге, чтобы в меньшей мере использовать добавки каких-либо отощителей. Здесь очень важно провести тщательное смешение состава формовочной массы. Нами было проведено смешение влажной и второй сухой молотой глины, чтобы получить наиболее однородную массу. Образцы таких глин отобраны для естественнонаучных исследований. Подтверждение такой гипотезы было найдено в современной этнографии, когда вместо отощителей использовали два вида глин.

Помимо вышеизложенного были проведены эксперименты по моделированию техники лощения по влажной и сухой поверхности сосудов, а также были опробованы приемы нанесения ангоба на поверхность сосудов. В качестве образцов для моделирования были использованы фрагменты с ангобом из поселения Ракушечный Яр и из поселений эпохи ранней бронзы Северного Кавказа. В Комплексной экспедиции ИИМК РАН нами были апробированы два вида нанесения ангоба: 1 - жидким красящим раствором; 2 - сметанообразным по своей консистенции составом из тонко отмученной глиняной массы красящего состава. Ангоб наносился по гладкой обработанной и заглаженной поверхности с одной стороны или с обеих сторон на венчике сосуда или по всей внешней поверхности.

За годы исследований в Комплексной экспедиции ИИМК РАН было смоделировано несколько разных приемов обжига готовых сосудов. Обжиг проводился в костре, над костром, в ямах различной глубины. Проводились попытки опытным путем найти наиболее соответствующие условия обжига. Моделирование процесса обжига проводилось как для керамики эпохи неолита, так и для керамики эпохи ранней бронзы Северного Кавказа. Здесь было важно выяснить, можно ли смоделировать высокотемпературный обжиг для керамики эпохи бронзы в ямах, так как для этого времени известно всего две гончарные печи, обнаруженные на поселениях Псекупс и Пхагугапе на Северном Кавказе. Обжиг проводился с использование тонких плодовых деревьев и их веток и сухого тростника. Как известно, эти материалы дают высокую температуру при их сгорании. Именно такое сочетание позволило достичь температуры обжига от $850^{\circ} \mathrm{C}$ до $1000^{\circ} \mathrm{C}$. Замеры температуры костра с расстояния 3 м до него показали, что она составляла $750^{\circ} \mathrm{C}$, при наличии ветра и прохладной погоды в октябре. Внутри костра, в самом его центре, температура была значительно выше. Петрографический анализ нескольких полученных образцов, проведенный М.А. Кульковой, из эксперимента при моделировании с костровым обжигом неолитической керамики показал, что фрагменты керамики, находившиеся на периферии очага, имели температуру обжига $650-700^{\circ} \mathrm{C}$, а у образцов керамики из эпицентра костра она достигает до $850-900^{\circ} \mathrm{C}$.

В заключение можно сказать, что комплексный подход и использование нескольких методов исследования керамического материала позволяет сделать не только более точные как технологические, так и исторические реконструкции, но и определить технику изготовления древней керамики. Такой подход помогает выяснить приемы лепки сосудов, их размеры, характер использованного сырья, его подготовку к применению, а также установить все добавленные в глиняное тесто примеси и температурный режим обжига готовой керамики.

\section{Список литературы:}

1. Поплевко Г.Н. Экспериментальное моделирование керамических форм эпохи неолита // Геология, Геоэкология, Эволюционная география. Т. Х: сб. науч. тр. / под ред. Е.М. Нестерова. СПб.: Изд-во РПГУ им. А.И. Герцена, 2010. С. 173-176.

2. Поплевко Г.Н. Технология изготовления майкопской керамики // Цивилизационные центры и первобытная периферия в эпоху раннего металла: модели взаимодействия: тезисы докладов круглого стола. М.: Институт археологии РАН, 2013. С. 29-31.

3. Поплевко Г.Н. Об устойчивости культурной традиции в технологии изготовления керамики (на примере данных археологии и этнографии) // Культура русских в археологических исследованиях: матлы V междунар. науч. конф. 24-28 ноября 2014 г. в Тюмени. Тюмень, 2015. С. 118-124.

4. Поплевко Г.Н. Технология изготовления керамики в энеолите - раннем бронзовом веке на СевероЗападном Кавказе // Кавказ как связующее звено между Восточной Европой и Передним Востоком: диалог культур, культура диалога (к 140-летию Александра А. Миллера). СПб.: ООО «Невская книжная типография», 2015. С. 169-174.

5. Поплевко Г.Н. Методический подход к комплексному исследованию древней керамики // Coвременные подходы к изучению керамики в археологии. М.: ИА РАН, 2015. С. 111-132.

6. Поплевко Г.Н. Комплексный подход к исследованию древней керамики и возможности экспериментально-трасологических исследований // Древний Тургай и Великая степь: часть и целое. Костанай-Алматы: ТОО «Костанайполиграфия», 2015. С. 255-266.

7. Поплевко Г.Н. Культурные и технологические традиции изготовления профилированной керамики (по данным археологии, этнографии и эксперимента) // Изучение и сохранение археологического наследия народов Кавказа: материалы междунар. науч. конф. по археологии Северного Кавказа. 18-21 апреля 2016 г. Грозный: Чеченский государственный университет, 2016. С. 291-294.

8. Поплевко Г.Н. Комплексный подход в изучении древней керамики и реконструкция культурных 
традиций // V (XXI) всерос. археологический съезд: сборник научных трудов. 2017. С. 845-846.

9. Поплевко Г.Н. Некоторые приемы формовки майкопской керамики // Проблемы археологии Кавказа и Передней Азии. Баку: Афполиграф, 2017. С. 176-199.

10. Поплевко Г.Н. Методический подход к комплексным трасологическим, экспериментальным и естественнонаучным исследованиям // Этническая история и культура тюркских народов Евразии. Омск: Издатель-Полиграфист, 2011. С. 376-379.

11. Поплевко Г.Н. Статистический анализ керамики нижних слоев неолитического поселения Ракушечный Яр и некоторые экспериментальные наблюдения по ее орнаментированию // Археологические источники и культурогенез. Таксоны высокого порядка в системе понятий археологии каменного века. Тез. докл. СПб.: СПбГУ, 2011. С. 100-106.

12. Поплевко Г.Н. Методика экспериментальных исследований по моделированию лепной керамики // Материалы III археологического съезда. Старая Русca, 2011. C. 399-401.

13. Поплевко Г.Н. Эксперименты по лепке и обжигу лепной керамики // Неолит Среднего Поволжья в системе культур Евразии: мат-лы междунар. науч. конф. (г. Самара, 17-18 июня 2011). Самара: ПГСГА, 2011. C. 24-27.

14. Поплевко Г.Н. Эксперименты по лепке сосудов из разных глин на твердой основе // Экология древних и традиционных обществ: сборник докладов конф. Вып. 4. Тюмень, 2011. С. 136-139.

15. Поплевко Г.Н. Эксперименты по формовке и обжигу лепных керамических сосудов // Проблемы археологии Кавказа (к 70-летию Ю.Н. Воронова): сб. мат-лов межд. науч. конф., посв. 70-летию Ю.Н. Воронова. Сухум: РУП «Дом печати», 2011. С. 45-52.

16. Поплевко Г.Н. Экспериментальное моделирование керамики эпохи неолита // Археологические записки. Ростов-на-Дону: Донское археологическое об-во, 2012. Вып. 7. С. 342-353.

17. Поплевко Г.Н. Комплексное исследование и реконструкция древних технологий (методический аспект): сборник научных трудов международного симпозиума «Интеграция археологических и этнографических исследований. Т. 1. Иркутск, Омск. Изд-во ИрГТУ, 2013. С. 145-150.
18. Поплевко Г.Н. Экспериментальное моделирование ручной лепки сосудов неолита-бронзы // Историко-археологические исследования в Азове и на Нижнем Дону в 2012 году. Вып. 28. Азов: Издательство Азовского музея-заповедника, 2014. С. 170-182.

19. Поплевко Г.Н. Технологические приемы изготовления керамики неолита-бронзы (по данным археологии, этнографии и экспериментального моделирования) // Проблеми вивчення та охорони пам'яток первісного мистецтва півдня Свропи (кам'яний вік - епоха бронзи). Збірник наукових праць міжнародної наукової конференції. Запоріжжя: Дике Поле, 2015. C. 94-118.

20. Поплевко Г.Н., Кулькова М.А. Комплексное исследование керамики из нижних слоев поселения Ракушечный Яр и экспериментальных образцов из источников глин вблизи него // Археологические источники и культурогенез. Таксоны высокого порядка в системе понятий археологии каменного века. Тезисы доклада. СПб.: СПбГУ, 2011. С. 107-119.

21. Белановская Т.Д. Из древнейшего прошлого Нижнего Подонья. СПб.: Изд-во СПбГУ, 1995. 199 с.

22. Мазуркевич А.Н., Долбунова Е.В. Древнейшая глиняная посуда Восточной Европы: технология, морфология и орнаментация (по материалам 23-14 слоев памятника Ракушечный Яр) // Краткие сообщения института археологии. Вып. 227. М.: Языки славянской культуры, 2012. С. 286-295.

23. Мазуркевич А.Н., Долбунова Е.В., Кулькова М.А. Древнейшие керамические традиции Восточной Европы // Российский археологический ежегодник. СПб.: Университетский издательский консорциум, 2013. С. 27-108.

24. Мазуркевич А.Н., Долбунова Е.В., Кулькова М.А. Еще раз об изучении древнейшей керамики Восточной Европы (ответ оппонентам) // Российский археологический ежегодник. СПб.: Университетский издательский консорциум, 2013. С. 133-139.

25. Поплевко Г.Н. К проблеме комплексного исследования и реконструкции древней керамики // Традиции и инновации в изучении древнейшей керамики: программа междунар. конф. 24-27 мая 2016 г. Санкт-Петербург, 2016.

Работа выполнена при финансовой поддержке РФФИ, проект № 18-09-00568 A.

\section{COMPLEX EXPERIMENTAL-TRASOLOGIC AND ETHNOGRAPHIC RESEARCHES OF CERAMICS: TECHNOLOGY OF MANUFACTURING AND BURNING}

(C) 2018

Poplevko Galina Nikolaevna, candidate of historical sciences,

senior researcher of Experimental and Traceology Laboratory

Institute of History of Material Culture of the Russian Academy of Sciences (Saint Petersburg, Russian Federation)

Abstract. Complex experimental-trasological and ethnographic studies of ceramics are shown on the example of their application to the study of technological methods for the manufacture of ancient ceramics. The paper considers the use of different research methods using the materials of Rakushechny Yar settlement on the Lower Don and Maikop culture in the North Caucasus and ethnographic data. Experimental modeling of flat-bottomed vessels of the Neolithic and round-bottomed vessels of Maikop culture is given as an example. It is shown that ceramics in different archaeological epochs were made using several techniques. The technique of making vessels was modeled by experiments. The study of ethnographic data on the technique of making round-bottomed vessels shows that the methods of modeling different vessels are much larger. The work presents archaeological, experimental, tracological and ethnographic data on the production of both flat-bottomed and round-bottomed vessels using the knockout technique. Recently, with the help of this technique, a series of experiments on the modeling of vessels and the subsequent tracological study of the technology of their manufacture with the help of a knockout was performed. For the first time the author shows the use of a combination of various methods of modeling in the manufacture of Neolithic vessels. The data of petrography and experiments on the burning of vessels are given.

Keywords: archeology; complex study of ceramics; ethnographic studies of modeling ceramics; analysis of ceramic analysis; ceramic analysis; manual modeling of ceramics; technique of round-bottomed vessels; experimental modeling; petrographic analysis of ceramics. 